\title{
Transmission planning in a deregulated environment
}

\author{
Xu, Zhao
}

Published in:

IEE Proceedings - Generation Transmission and Distribution

Link to article, DOI:

10.1049/ip-gtd:20050201

Publication date:

2006

Document Version

Publisher's PDF, also known as Version of record

Link back to DTU Orbit

Citation (APA):

$\mathrm{Xu}, \mathrm{Z}$. (2006). Transmission planning in a deregulated environment. IEE Proceedings - Generation Transmission and Distribution, 153(3), 326-334. https://doi.org/10.1049/ip-gtd:20050201

\section{General rights}

Copyright and moral rights for the publications made accessible in the public portal are retained by the authors and/or other copyright owners and it is a condition of accessing publications that users recognise and abide by the legal requirements associated with these rights.

- Users may download and print one copy of any publication from the public portal for the purpose of private study or research.

- You may not further distribute the material or use it for any profit-making activity or commercial gain

- You may freely distribute the URL identifying the publication in the public portal

If you believe that this document breaches copyright please contact us providing details, and we will remove access to the work immediately and investigate your claim 


\title{
Transmission planning in a deregulated environment
}

\author{
Z. Xu, Z.Y. Dong and K.P. Wong
}

\begin{abstract}
The worldwide trend for the deregulation of the electricity generation and transmission industries has led to dramatic changes in system operation and planning procedures. The optimum approach to transmission-expansion planning in a deregulated environment is an open problem especially when the responsibilities of the organisations carrying out the planning work need to be addressed. To date there is a consensus that the system operator and network manager perform the expansion planning work in a centralised way. However, with an increasing input from the electricity market, the objectives, constraints and approaches toward transmission planning should be carefully designed to ensure system reliability as well as meeting the market requirements. A market-oriented approach for transmission planning in a deregulated environment is proposed. Case studies using the IEEE 14-bus system and the Australian national electricity market grid are performed. In addition, the proposed method is compared with a traditional planning method to further verify its effectiveness.
\end{abstract}

\section{Introduction}

Conventionally power-system expansion planning, including both generation-expansion and transmission-expansion planning, is performed solely by the system operator, and is therefore known as centralised planning [1, 2]. In transmission expansion planning, the task is to determine when and where new transmission facilities should be installed so that they operate in an optimal manner, subject to a list of technical, financial and environmental constraints. This is also referred to as least-cost planning because the optimal solution is to minimise the value of the capital required for a planned scheme. A reliability assessment that includes both capacity adequacy and a system security assessment is also a key part of the planning process. Transmission-expansion planning is inherently a dynamic problem, since the planning horizon usually covers a long time period, for instance, 5,10 or 20 years into the future [2], and thus dynamic properties of the power system have to be carefully considered in the planning process.

Expansion planning is a highly complex problem, where solution often involves the use of sophisticated mathematical modelling and intensive numerical computations. This complex task is usually decomposed into two successive steps, with the first step being the identification of candidate circuits for expansion, and the second step being the selection of a best subset from the pool. The second step is the focus of this study.

The focus of traditional centralised planning less in minimising the total investment capital required for a scheme while still fulfilling the obligation to reliably supply

(C) The Institution of Engineering and Technology 2006

IEE Proceedings online no. 20050201

doi:10.1049/ip-gtd:20050201

Paper first received 25th May and in final revised form 22nd August 2005

Z. Xu and Z.Y. Dong are with School of Information Technology and Electrical Engineering, The University of Queensland, St. Lucia, QLD 4072, Australia

K.P. Wong is with Department of Electrical Engineering, The Hong Kong Polytechnic University, Hung Hom, Kowloon, Hong Kong

E-mail: zydong@ieee.org energy [1-7]. In traditionally regulated environments, power utility stakeholders play a decisive role in the power-system planning process. These key stakeholders include [8]:

- The staff of the regulated utility (management and planners);

- regulators;

- customers;

- the shareholders or owners of the utility;

- investors from the financial markets.

The planning objective in a regulated environment is to minimise the total revenue required to implement a resource plan [8] and thus it is basically a least-cost planning approach [9]. Because of regulations, planners normally have the power system data required for expansion planning, such as demand forecasts, existing generators, fuel prices, existing and planned resources and the required financial return on investment. It is noted that due to deregulation of the industry not all of this information is now available to transmission-system planners.

The deregulation of the power industry has resulted in the separation of the industry into generation, transmission and distribution entities. The developed generation providers compete in the open electricity market so as to maximise their profits. The operation and management of the industry are designed to ensure open access and competitiveness in the market place. Since transmission and other various ancillary services are now commodities, expansion planning should now include their market impacts in the decision-making process. In addition planning is no longer dominated by system operators since the private sector is becoming increasingly involved in the industry [4-6]. As identified in [8], the key stakeholders in the new deregulated power utilities include:

- power plant owners;

- transmission providers;

- regional transmission operators;

- power marketers and load-serving entities; 
- regulators;

- customers;

- shareholders in companies that build new facilities; and

- Investors from the financial markets.

The significant change in stakeholder profiles is resulting in changes in the planning process since the traditional planning approach is now no longer appropriate in this new era. Consequently, expansion-planning modelling should now consider not only the investment level but also market prospects created by the expansion. This is especially important for private investors who tend to have marketoriented objectives. We intend to use the transmission network expansion planning (TNEP) problem as an example to propose a planning method capable of meeting the challenges arising from deregulation. Based on the traditional methods, the proposed market-oriented planning approach will maximise the overall social benefit of expansion projects, which is consistent with the ultimate goal of the deregulation. The IEEE 14-bus system and a simplified Australian national electricity market (NEM) grid model will be used to test the proposed method. A genetic algorithm will be used to optimise the planning objective.

\section{State-of-the-art planning in a deregulated enviornment}

Transmission planning in a competitive market is mainly driven by market needs with the proviso that certain constraints, such as reliability, security and economic factors are satisfied. There are already different planning processes being used. Some of the typical practices are reviewed here to demonstrate current thinking on how to deal with the challenge of transmission planning in a deregulated environment. These practices include those of the Bonneville Power Administration (BPA) and the Electric Power Research Institute (EPRI) [10-12].

\subsection{Market Impact}

The deregulation of the transmission system has resulted in demands for improved power system transmissionexpansion planning techniques. In a competitive market with deregulated generation companies, trading is performed in terms of the transmission system and/or financially. Consequently, transmission pricing is important in promoting the efficient use and expansion of the transmission grid in a competitive market. Specifically, transmission price signals result in two types of transmission-planning projects: (i) network-transmission projects which are designed to enhance the overall transmission capability of a regional network (e.g. the new interconnectors planned by the new management company (NEMM$\mathrm{CO}$ for the NEM); and (ii) dedicated transmission projects, e.g. interconnectors in the NEM planned by enterpreneural private investors. Accordingly, there are two types of transmission-planning approaches: (i) central planning for transmission projects to enhance the overall transmission capability: and (ii) decentralised planning by individual investors using normal commercial incentives to drive specific transmission projects. Generally speaking, centralised planning is currently receiving more attention especially after several major blackouts in 2003 that are generally regarded as partially being due to an insufficient transmission capacity for the overall power grid. Fully decentralised transmission planning still needs more research before it can be practiced universally.

\subsection{Project-Specific Transmission-Planning Processes}

The BPA transmission line expansion-planning process to meet the anticipated needs of its customers is summarised in [10]. The process is regarded as being reactive [11] because it is driven by events external to the transmission line. These events include generation or customer interconnection requests and compliance with legal, regulatory, safety and reliability requirements. These events are used in the screening, evaluation, development of different planning options and selection of the preferred expansion plan. They are also used to ensure compliance with the NERC and WSCC reliability requirements. The National Environmental Policy Act and the implementation process that includes construction and rate-making also use these events [10].

Orans et al. [11] propose a revised transmission line expansion process based on the existing BPA's projectspecific planning process. The revised process includes recommendations for: (i) the improvement of load forecasts so as to remove the incentive for utilities to overestimate the peak load requirement in their submitted forecasts [10]; (ii) quantification of the cost and reliability consequences for not building suggested projects; (iii) evaluation of alternatives to transmission planning including demand management and distributed generation; (iv) evaluation of potential market impacts of new transmission investments; and (v) implementation of the modifications recommended by BPA in the selection of preferred transmission plans. These factors basically initiate a centralised approach to the planning process; and provide means to fix possible market constraints or reliability problems [11]. In the BPA approach, several criteria with deferring are used in the economic screening stage of the planning process and they include the transmission avoidance costs, which are costs associated line investments that result in increased operation and management costs that in turn lead to increases in the revenue requirement [11].

\subsection{Uncertainties in the Electricity Market and Probabilistic Planning}

It is generally recognised that, the power-system planning has to consider the impact of uncertainties on the power system. Contingency screening for system reliability and a security assessment are examples of handling system uncertainties that can also take the form of uncertainties in: (i) forecasting; (ii) facility performances; (iii) power system contingencies; and (iv) market interactions. Based on a survey of a group of major utilities in the US, EPRI $[8,12]$ recommends the use of a probabilistic planning approach to handle the challenges associated with the deregulated environment. The sharing of planning data is recommended in this approach; however, due to uncertainties and the different interests of the various power utility stakeholders, the planning objective may differ from individual planners. Usually, planning in a deregulated environment involves the objectives of maintaining system reliability, minimising risks, improving market efficiency, minimising customer impact, and maximising profit [8]. It is also noted that the traditional $n-1$ criterion used in reliability assessment has problems in covering all the uncertainties in a deregulated environment. Accordingly EPRI has proposed its probabilistic risk assessment approach, however, EPRI has indicated the need to develop alternative probabilistic tools for planning that are flexible enough to accommodate the evolution of existing organisations and the emergence of new organisations in a deregulated environment.

We reiterate the point that any proposed technique for transmission expansion planning should be able to handle 
the impacts of deregulation, particularly uncertainties and risks. Recent proposals include the use of market measurement as well as traditional reliability and security assessment to obtain optimal planning options [13].

In the following sections, we will propose a comprehensive transmission-expansion planning process that is suitable for application to deregulated environments.

\section{Benefit of expansion-based transmission planning in a competitive electricity market}

\subsection{Selection of Candidate Circuits}

The first step in the proposed method is the formulation of an initial candidate pool for expansion that is based on information about a given system, such as the generation and transmission capacity, the estimated transmission tariffs for new circuits, the planning horizon and corresponding forecasted system demand etc. To ensure its compliance with practical engineering and management considerations, both a planner's experience and rules for guidance are needed, which may include but need not be limited to [1-6]:

- network redundancy;

- environmental factors;

- financial limits;

- estimated construction time of lines and the time horizon of the planning.

The pool is first formulated with so as to have redundant transmission lines as required for system reliability. By examining the investment requirements and construction periods of individual lines, a number of candidates can be dropped at this stage thereby avoiding an excessive workload in the following steps. By taking into account environmental factors, a further reduction in the pool size can be made, for example, a line should not be constructed through an important nature reserve.

\subsection{The optimisation model}

Once the pool of candidate circuits is formulated, the second step is to model the decision process for the expansion planning. Since the TNEP problem is fairly complex the modelling of the decision making involved in TNEP is usually simplified to a static optimisation problem with the aim of minimising the total investment using constraints so as to meet future demands and generation configurations. In practice, static transmission network expansion planning (STNEP) requires careful evaluation, since the cost of network construction is usually quite large. Sometimes a slight change in the expansion plan can result in the saving of a significant amount of capital. Based on the traditional method, we now intend to propose a marketoriented planning objective for the STNEP problem, although the underlying idea is not limited to this topic. The proposed method maximises the benefit of expansion (BOE), defined as the expected transmission profit from the expanded circuits net of the investment and cost due to inadequate transmission capacity, i.e. the cost of load losses subject to system and financial constraints. To account for the time value of capital, the net present-worthed BOE is used in the proposed method by assuming that the investment happens at the beginning of the planing year and new circuits are immediately ready for use. In addition, it also assumes that the transmission income and any loss due to lost loads happens at the middle of the planing year.
Equation (1) presents the proposed planning objective:

$\max$

$$
\begin{aligned}
B O E= & \alpha \frac{P(\boldsymbol{f}, \boldsymbol{\eta}, \boldsymbol{r}, \boldsymbol{d})}{(1+\mu)^{h+0.5}}-\beta \frac{\boldsymbol{C}^{T} \boldsymbol{\eta}}{(1+\mu)^{h}} \\
& -\gamma \frac{\left(\boldsymbol{U}^{T} \boldsymbol{L}\right) \text { VoLL }}{(1+u)^{h+0.5}}
\end{aligned}
$$

subject to

$$
\begin{gathered}
\boldsymbol{S}^{T} \boldsymbol{f}+\boldsymbol{g}+\boldsymbol{L}=\boldsymbol{D} \\
f_{i j}-\left(x_{i j}^{0}+x_{i j}\right)\left(\theta_{i}-\theta_{j}\right)=0 \\
\left|f_{i j}\right|-x_{i j} \xi_{i j} \leq x_{i j}^{0} \xi_{i j} ; \xi_{i j}=\frac{f_{i j}^{\max }}{x_{i j}^{0}} \\
0 \leq \boldsymbol{g} \leq \boldsymbol{g}^{\max } ; 0 \leq \boldsymbol{L} \leq \boldsymbol{D} \\
x_{i j}=\boldsymbol{\eta}_{i j} x_{i j}^{0}, 0 \leq \eta_{i j} \leq \eta_{i j}^{\max } \forall(i, j) \in \Gamma
\end{gathered}
$$

where $\theta_{i}$ and $\theta_{j}$ are bus voltage angles and are unbounded, $\boldsymbol{P}(\boldsymbol{f}, \boldsymbol{\eta}, \boldsymbol{r}, \boldsymbol{d})$ is the function of expected transmission profit from expanded lines, $\boldsymbol{C}$ is the vector of new line investments, $\eta_{i j}$ is the number of extra circuits added to transmission corridor $i-j$, with $\eta_{i j}^{\max }$ being the maximum number of added new lines, $\xi_{i j}$ is the phase angle difference between buses $i$ and $j, \boldsymbol{U}$ is an array of ones, $\boldsymbol{L}$ is the vector of load losses, $\boldsymbol{S}$ is the node-branch incidence array, $f_{i j}$ is the real power flow in corridor $i-j, \boldsymbol{g}$ is the real power generation vector with $\boldsymbol{g}^{\max }$ being its upper limit, $\boldsymbol{D}$ is the vector of forecasted demand, $x_{i j}$ is the total susceptance added to transmission corridor $i-j$, and $x_{i j}^{0}$ is the initial susceptance of branch $i-j, \Gamma$ is the candidate set for expansion, $\alpha, \beta$ and $\gamma$ are penalty factors of each term in the objective, VoLL is the value of the lost load, $h$ is the planning year and $\mu$ is the discount rate. For demonstration purposes, VoLL value of $\$ 1000 / \mathrm{MWh}$ is used in our case study, which does not resemble those used in actual systems, such as the A $\$ 10000 /$ MWh for the Australian NEM [14]. It should be noted that the penalty factors in the objective are introduced to ensure that the objective function stays positive. For simplicity, the value of $\alpha$ is assigned as unity in our case studies, whereas $\beta$ and $\gamma$ are selected through empirical observation to ensure a reasonably quick convergence for the optimisation, although different values may have a certain impact on the final expansion plan.

Equations (2) and (3) basically require the power flow to satisfy the circuit laws whereas (4) and (5) set the operation limits. Equation (6) specifies the range of the expansion decision parameters. The expected transmission profit $\boldsymbol{P}(\boldsymbol{f}, \boldsymbol{\eta}, \boldsymbol{r}, \boldsymbol{d})$ should be calculated based on the correct pricing of the transmission service. The considered transmission service is limited to real power transmission and other services, i.e. ancillary services, are not taken into account, although they can be added without much difficulty. Quite a few methodologies are available to recover the costs of transmission including: (i) the allocation pricing method; (ii) the postage stamp method; and (iii) the contract path method [15-17]. The transmission profit is based on the megawatt-mile pricing method as in (7), which has the advantage of closely resembling the operation of actual systems [15-17]:

$$
P(\boldsymbol{f}, \boldsymbol{\eta}, \boldsymbol{r}, \boldsymbol{d})=\sum\left|f_{i j}\right| r_{i j} d_{i j} \frac{\eta_{i j}}{\eta_{i j}+1} \forall(i, j) \in \Gamma
$$

where $d_{i j}$ is the length of branch $i-j, r_{i j}$ is the predetermined profit rate per unit capacity of the transmission line and is in units of dollars per megawatt mile. The concept of a unit transmission profit is similar to the cost per unit capacity of 
transmission lines in the original megawatt-mile method [17]. The difference is that the unit cost in the megawattmile method is bound per energy transaction, whereas our unit profit is not. Equation (7) requires the assumption that every line in a corridor has the same capacity, length and per unit transmission profit.

In (1), the expected profit can be considered to be the difference between consumers' payments and suppliers' costs or price in future transmission contracts, which is actually the social benefit from future transmission transactions [18]. Maximising the social benefits is undoubtedly the first priority in the marketplace, and it certainly should be reflected in the planning stage if considering the market planning and operation as a single process. Similarly, investment in expansion and the load loss costs can also be considered as 'costs' for the suppliers, assuming that they may not be fully recovered by the profit. Thus, the planning objective is formulated so as to maximise the overall $\mathrm{BOE}$, namely the net profit of the two parts. The proposed method actually seeks to maximise the overall social benefit from expansion by incorporating all factors of interests into one objective.

We will focus our attention on a market-oriented TNEP planning method for deregulated environments. It should be noted that the proposed planning approach is based on the assumption that other planning considerations, such as demand forecasting, reliability analysis, generation expansion and transmission line design have already been, performed. No security assessment of the final expansion plan is performed since it is not the main focus of this work.

\section{Application of a genetic algorithm to the planning problem}

The proposed planning objective actually formulates a mixed-integer nonliner optimisation problem. One possible method to solve the planning objective is to use the Bender decomposition method. However, this method does not ensure a global optimum if the problem is not convex, similar to other linear methods [1]. Therefore, genetic algorithms (GAs) that have a global search capability are used in our approach. The GA concept was introduced by Holland [19] and is based on Darwin's theory of natural selection. It starts with a set of initial solutions, called the initial population, randomly selected from the feasible solution space. The population then evolves through several operations such as reproduction, crossover and mutation to reach the final solution $[19,20]$. GAs have many useful properties including fewer mathematical requirements and greater flexibility of implementation which have influenced our choice to use GAs in our approach.

The implementation of a GA requires the generation of a population of candidate transmission lines. The proposed method uses one gene to represent one expansion route [1]. Inside each gene, an allele represents the number of lines to expand in the transmission route. Figure 1 illustrates the gene representation of the expansion problem with the transmission network being represented by the branches A to D. Obviously, a gene with all zero-valued alleles represents the original network without expansion. The fitness function of a GA has major influence on the final optimisation result. Therefore, it should reveal the influences of all factors of interest to the planner. In most cases, it is necessary to convert a known objective function into a practical one suitable for GA optimisation. Since the power flow equilibrium is essential in planning expansion, the objective (1) is modified to a new fitness function (8) by

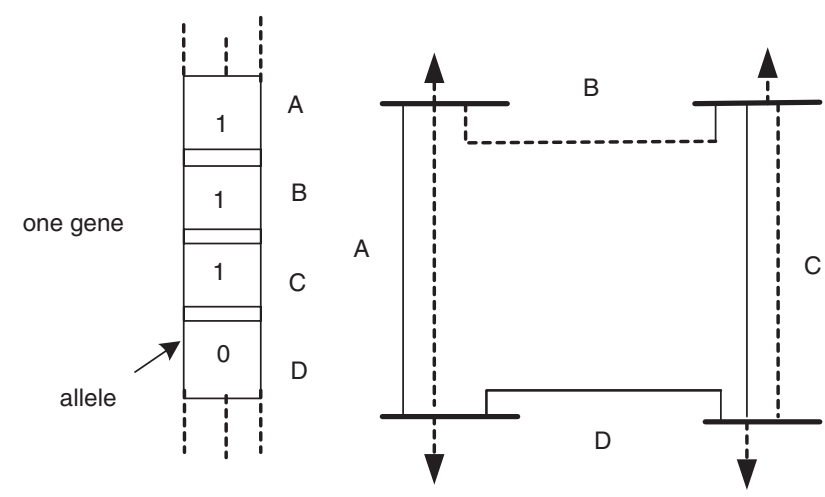

Fig. 1 Gene representation of the TNEP problem

multiplying a filter function (9) to reveal this critical condition [20].

$$
\begin{gathered}
\text { Fitness }=T_{1} \times T_{2} \\
T_{2}=e^{-\frac{\|g(x)\|^{2}}{k}}
\end{gathered}
$$

where $g(x)$ is the network flow balance equation, i.e. the mismatch in (2) and $k$ is a constant to control the 'bandpass' of the filter, $T_{1}$ is objective (1) and $T_{2}$ is the filter function. If $k$ is small, say 0.01 , only those $k$ values that ensure a $g(x)$ value close to zero can 'pass' the filter. By doing so, only those individuals satisfying the load flow condition will be assigned a meaningful fitness value for further optimisation in the GA. Those who have violated the condition will be assigned a small fitness value and will eventually die out over generations. The GA evolution is stopped when a predefined maximum number of generations is reached or the best individual remains unchanged over a predefined number of generations. Several techniques have been proposed to enhance the search ability of GAs, including, elitism, mutation probability control and sharing function methods. Mutation probability control ensures the search diversity of GAs [21-23].

\section{Case study}

\subsection{The IEEE 14-bus System Case}

The IEEE 14-bus system shown in Fig. 2 is used in the case study to test our proposed method. The system initially has

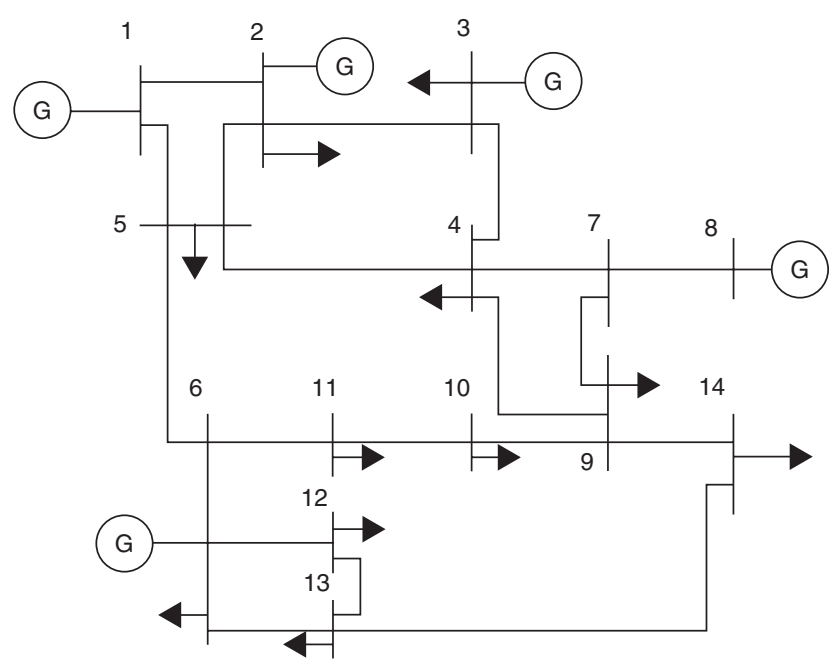

Fig. 2 The IEEE 14-bus system 
a total of 20 transmission corridors. Important parameters of the system are summarised in Tables 1 and 2. The reactance in the tables is in p.u. with a base of $100 \mathrm{MW}$.

Table 1: System generation data

\begin{tabular}{ll}
\hline Bus & Generation capacity, MW \\
\hline 1 & 250 \\
2 & 200 \\
3 & 60 \\
6 & 50 \\
8 & 60 \\
\hline
\end{tabular}

Table 2: Data for the transmission branches

\begin{tabular}{rlll}
\hline No & Branches & Reactance p.u. & Capacity, MVA \\
\hline 1 & $1-2$ & 0.05917 & 120 \\
2 & $1-5$ & 0.22304 & 60 \\
3 & $2-3$ & 0.19797 & 60 \\
4 & $2-4$ & 0.17632 & 60 \\
5 & $2-5$ & 0.17388 & 60 \\
6 & $3-4$ & 0.17103 & 60 \\
7 & $4-5$ & 0.04211 & 60 \\
8 & $4-7$ & 0.2045 & 60 \\
9 & $4-9$ & 0.5389 & 60 \\
10 & $5-6$ & 0.2349 & 60 \\
11 & $6-11$ & 0.1989 & 60 \\
12 & $6-12$ & 0.25581 & 60 \\
13 & $6-13$ & 0.13027 & 60 \\
14 & $7-8$ & 0.17615 & 60 \\
15 & $7-9$ & 0.11001 & 60 \\
16 & $9-10$ & 0.0845 & 60 \\
17 & $9-14$ & 0.27038 & 60 \\
18 & $10-11$ & 0.19207 & 60 \\
19 & $12-13$ & 0.19988 & 60 \\
20 & $13-14$ & 0.34802 & 60 \\
\hline & & &
\end{tabular}

In this case study candidate circuits for network expansion have been predetermined from the first step of the proposed TNEP method. These circuits have different characteristics. Given the proposed objective for network planning, the important characteristics of those circuits include the circuit length, the expected transmission tariffs and the maximum number of circuits to be added in a corridor etc. The data used in the simulation studies presented in Table 3, which does not necessarily resemble an actual real system.

The testing program was developed using MATLAB ${ }^{\mathrm{TM}}$. Two expansion cases were studied. The parameter $\alpha$ in the fitness function was assigned a value of unity in both cases with $\beta$ and $\gamma$ being empirically assigned as 0.01 and 0.02 respectively to ensure a fast convergence of the problems. These factors actually account for a planner's preference in the proposed multiobjective optimisation model [24]. Therefore, the selection of appropriate values should involve planners performing careful analyses, based on simulations and/or experience. Without losing generality, the values in this case study were chosen for demonstration purposes only. A discount rate of $4.0 \%$ was used in all the case
Table 3: Candidate transmission routes for expansion

\begin{tabular}{rllll}
\hline No & $\begin{array}{l}\text { Max } \\
\text { expansion }\end{array}$ & $\begin{array}{l}\text { Length, } \\
\text { miles }\end{array}$ & $\begin{array}{l}\text { Profit rate, } \\
\$ / \text { MW-mile }\end{array}$ & $\begin{array}{l}\text { Construction } \\
\text { cost } \$\end{array}$ \\
\hline 3 & 1 & 30 & 2.0 & 200000 \\
6 & 1 & 30 & 2.0 & 160000 \\
11 & 2 & 30 & 2.0 & 180000 \\
12 & 1 & 45 & 3.0 & 240000 \\
15 & 1 & 15 & 1.0 & 190000 \\
16 & 1 & 15 & 1.0 & 120000 \\
18 & 1 & 30 & 2.0 & 130000 \\
20 & 2 & 40 & 3.0 & 180000 \\
\hline
\end{tabular}

studies. The original IEEE 14-bus system has a total load of $259 \mathrm{MW}$, distributed unevenly among the system. In case 1 , the system load is expected to grow by $20 \%$ in 5 years, i.e. $h=5$ in (1). The simulation result shows that case 1 selects routes $3,16,18$ and 20 for expansion with only one circuit addition for each route. Figure 3 shows the performance of the GA for the first case. The GA converged within 63 iterations. The maximum, mean, minimum and standard deviation of the fitness function are presented in Fig. 3.

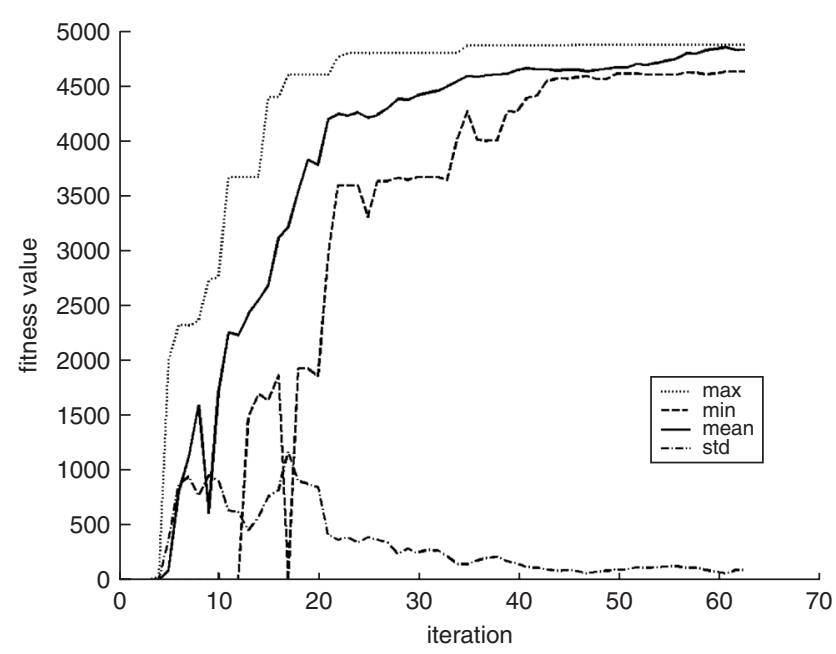

Fig. 3 The GA performance in case 1

The second case has a load growth of $60 \%$ over a 10 years period. Candidate routes 3, $611,16,18$ and 20 are selected for expansion making a total of six circuits to be expanded. This is not unreasonable since we are planning to satisfy a significant growth in demand. Figure 4 shows the final expansion plans of the two cases studied, with dashed lines representing the new transmission lines to be added. Table 4 summarises the simulation results of the two cases, where cases 1 and 2 have total investment requirements and capacity additions of $\$ 630000$ and $\$ 970000$ and 240 and $360 \mathrm{MW}$ respectively. Obviously, case 2 has a larger capacity addition and investment costs due to a larger demand.

The simulations for both cases were repeated for different values of $\beta$ and $\gamma$ in (1). It was found that the two parameters have no significant impact on the final optimisation results. However, they do affect the evolution process of the GA, smaller values of $\beta$ and $\gamma$ can enable a faster convergence of the GA and a larger final fitness value, which can be understood by reference to (1). 

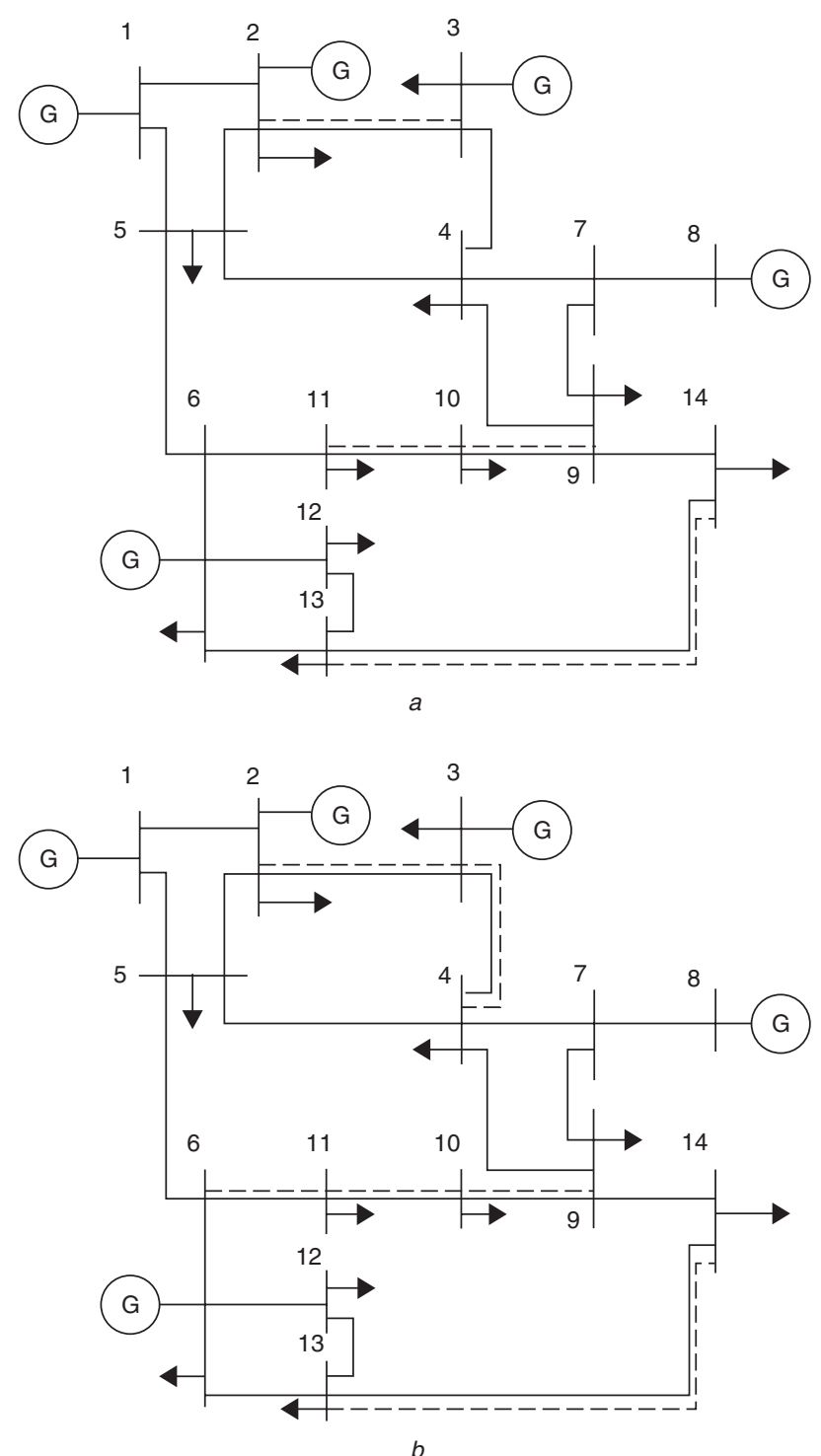

Fig. 4 Final expansion plans for cases 1 and 2 (dashed lines represent new lines to be expanded) $a$ Case 1

$b$ Case 2

Table 4: Simulation results for the case studies

\begin{tabular}{lll}
\hline No. & Case 1 & Case 2 \\
\hline 3 & 1 & 1 \\
6 & 0 & 1 \\
11 & 0 & 1 \\
12 & 0 & 0 \\
15 & 0 & 0 \\
16 & 1 & 1 \\
18 & 1 & 1 \\
20 & 1 & 1 \\
Total cost, $\$$ & 630000 & 970000 \\
Total capacity & 240 & 360 \\
addition, MW & & \\
\hline
\end{tabular}

Another interesting phenomenon observed is that the routes 3, 16, 18, 20 were always selected in both cases. This can be attributed to the network configuration as well as the higher transmission rate of individual routes, for instance, route 20 has the highest tariff among the candidate pool.

\subsection{The NEM Model Case}

Formally launched in 1998, the Australian NEM is a halfhourly pool market, which uses a system marginal price auction to make dispatching decisions. Up to seven billion Australian dollars worth of electricity is traded annually using the NEM with the traded electricity being supplied to nearly 8000000 customers. The NEM comprises of five interconnected regions who are intended to operate as a single national market rather than five separate regional markets [25]. Proposals by transmission service providers for new or augmented interconnections should be assessed and approved jointly by the inter-regional planning committee and the NEMMCO. Transfer capability (TC) is a major concern in transmission planning for the NEM, $[25,26]$. Considering the expected loading conditions and regulatory tests, power flows are calculated to determine the transfer limit or capacity of the interconnectors [25-27], however, the transmission profit has been paid less attention. Using the simplified NEM model as in Fig. 5, we compare the planning outcomes of the proposed technique and a TC-based approach.

The modelling of the NEM uses publically available information and consists of 14 generators and 30 buses and branches respectively. Four intercommunion corridors are in the model, connecting South Australia (SA) to Victoria (VIC), VIC to Snowy, Snowy to New South Wales (NSW), and NSW to Queensland (QLD). Originally, the system has a total load of $16069 \mathrm{MW}$ distributed unevenly into regions. For cases of calculation a capacity of $500 \mathrm{MW}$ is initially assumed for each interconnector. It is assumed that the load needs to be increased to $26979 \mathrm{MW}$ over a ten year horizon, which is equivalent to the total demand forecasted in NEM for Autumn, 2005, as shown in Table 5 [26].

The discount rate and penalty factors used in the simulation are the same as those in the previous case. The parameters for the interconnectors in this case are listed in Table 6. The GA optimisation converged within 61 iterations. As shown in Table 7, a total of seven lines have been added to the existing interconnectors with a total cost and capacity addition of $\$ 1450$ and $3500 \mathrm{MW}$ respectively. Table 6 also gives the forecasted maximum limits of the interconnector capacities for Autumn 2005, forecasted based on a TC-maximisation approach [27]. These limits can be regarded as the actual transmission capacities needed for the time considered, since it is difficult to get relevant information from the actual system. Compared to these limits, the proposed model gives different capacities for the same expected demand. This indicates that the inclusion of transmissions profit in the proposed method appears to change the expansion plan. Although other factors should also be taken into account. Consequently, the conclusion can be made that it may be necessary to consider the transmission profit in expansion planning in actual systems such as the Australian NEM, if a comprehensive evaluation of the situation is required.

\subsection{Comparison Study}

The proposed method has been successful tested in the previous Sections In order to further verify its effectiveness, the proposed is compared with a traditional TNEP method in [1]. The traditional method considers the construction costs and the cost due to load losses, and its objective 


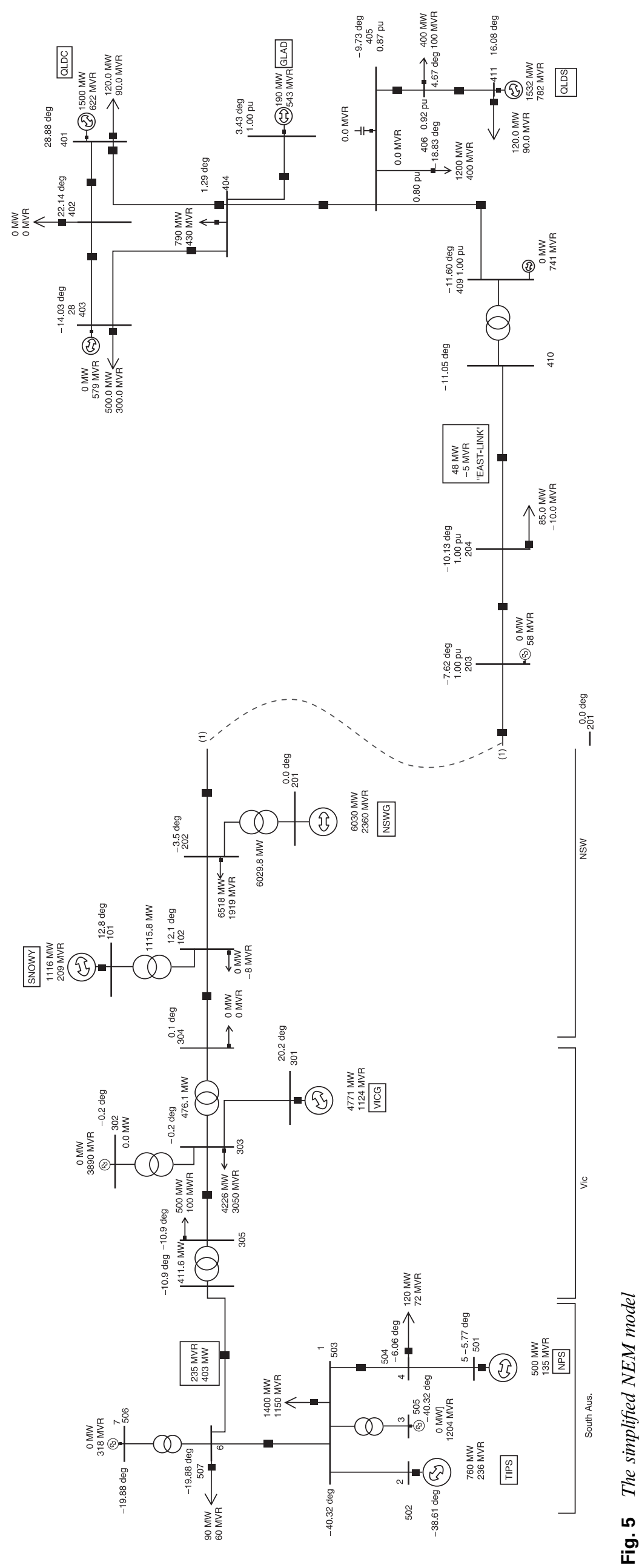


Table 5: Seasonal demand forecast for NEM with a $10 \%$ probability of exceedence [26]

\begin{tabular}{lcccc}
\hline Region & $\begin{array}{l}\text { Summer } \\
\text { 2004l2005 }\end{array}$ & $\begin{array}{l}\text { Autumn } \\
2005\end{array}$ & $\begin{array}{l}\text { Winter } \\
2005\end{array}$ & \multicolumn{1}{c}{$\begin{array}{l}\text { Spring } \\
2005\end{array}$} \\
\hline QLD & 8448 & 6918 & 7539 & 7094 \\
NSW & 13680 & 11516 & 13660 & 11967 \\
VIC & 9730 & 7543 & 8138 & 7664 \\
SA & 3312 & 1961 & 2581 & 2159 \\
\hline
\end{tabular}

*Snowy region has little demand and is not shown

Table 6: Candidate transmission routes for expansion

\begin{tabular}{llllll}
\hline Interconnector & $\begin{array}{l}\text { Max } \\
\text { expansion }\end{array}$ & $\begin{array}{l}\text { Length, } \\
\text { miles }\end{array}$ & $\begin{array}{l}\text { Profit rate, } \\
\$ / \text { MW-mile }\end{array}$ & Cost, $\$$ & $\begin{array}{l}\text { Capacity, } \\
\text { MW }\end{array}$ \\
\hline SA to VIC & 3 & 45 & 3.0 & 200000 & 500 \\
VIC to Snowy & 3 & 60 & 4.0 & 200000 & 500 \\
Snowy to & 3 & 60 & 4.0 & 210000 & 500 \\
NSW & & 45 & 3.0 & 220000 & 500 \\
NSW to QLD & 3 & & & &
\end{tabular}

Table 7: Simulation results for the NEM case

\begin{tabular}{llll}
\hline Interconnector & Expansion & $\begin{array}{l}\text { Capacity after } \\
\text { expansion, MW }\end{array}$ & $\begin{array}{l}\text { Max capacity } \\
\text { by TC, MW }\end{array}$ \\
\hline SA to VIC & 1 & 1000 & 645 \\
VIC to Snowy & 3 & 2000 & 1910 \\
Snowy to NSW & 1 & 1000 & 2740 \\
NSW to QLD & 2 & 1500 & 1040 \\
\hline
\end{tabular}

Table 8: Simulation results obtained using the proposed and traditional methods

\begin{tabular}{lll}
\hline Route & Proposed & $\begin{array}{l}\text { Traditional } \\
\text { method }\end{array}$ \\
\hline 3 & 1 & 1 \\
6 & 1 & 1 \\
11 & 1 & 2 \\
12 & 0 & 1 \\
15 & 0 & 0 \\
16 & 1 & 0 \\
18 & 1 & 1 \\
20 & 1 & 0 \\
Total cost, $\$$ & 970000 & 1090000 \\
Total capacity & 360 & 360 \\
addition, MW & & 1112.7 \\
Transmission & 1136.7 & \\
profit, $\$$ & & \\
\hline
\end{tabular}

function can be written as:

$$
\min \alpha^{\prime} \frac{\boldsymbol{C}^{T} \boldsymbol{\eta}}{(1+\mu)^{h}}+\beta^{\prime} \frac{\left(\boldsymbol{U}^{T} \boldsymbol{L}\right) \operatorname{VoLL}}{(1+u)^{h+0.5}}
$$

where $\alpha^{\prime}$ and $\beta^{\prime}$ are penalty factors and all the other parameters are as in (1). The traditional method is used to plan the expansion of the IEEE 14-bus system with a load growth of $60 \%$ as in case 2 of Section 5.1. A GA optimisation technique similar to that discussed in Section 4 is used in the simulation. Table 8 is a comparison of the expansion plans produced by using the new proposed and traditional methods. It shows that both methods select six lines for expansion with the same total capacity addition of $360 \mathrm{MW}$. However, our proposed method has a smaller cost of $\$ 970000$ compared to the $\$ 1090000$ of the traditional method.

In addition, dispatches of an ideal SMP-based market have been simulated by running optimal power flows on the expanded systems of the two methods. The total transmission profits of the two expanded systems have also been calculated using (7). It was found that our proposed method can earn more profit $(\$ 1136.7)$ than the traditional method $(\$ 1112.7)$ in such a market environment. Thus, it may be concluded that our proposed planning method can give better results in terms of total expansion cost and future transmission profit as compared to the traditional method.

\section{Conclusions}

To cope with the many uncertainties and challenges introduced by the deregulation of the electricity industry a transmission-planning approach that uses a GA is proposed. The proposed method has two significant features. Firstly, it adopts a market-oriented planning objective to maximise the present value of the overall benefits from expansion, which is consistent with the ultimate goal of deregulation. Secondly, GA which is an effective and reliable method to obtain global optimisation is used to solve the planning objective. The proposed method has been tested on two systems namely the IEEE 14-bus and simplified NEM models. Results have been analysed and compared with available information from actual systems. Comparisons with the traditional method have also been made, which show that the proposed method can produce an expansion plan that has a lower construction cost and a higher transmission income. Further work is underway to test the method on large-scale systems. The method will also be compared with other methods to further evaluate its effectiveness and long-term economic impacts. Furthermore, the method will be extended to dynamically plan transmission expansion with load growth over time.

\section{References}

1 Gil, H.A., and da Silva, E.L.: 'A reliable approach for solving the transmission network expansion planning problem using a genetic algorithm', Electr. Power Syst. Res., 2001, 58, pp. 45-51

2 El-Abiad, A.H. (editor): 'Power systems analysis and planning', 1981

3 Wang, X.F.: 'Fundamentals of Power System Planning' (China Electric Power Press, 1993)

4 Gorenstin, B.G., Campodonico, N.M., Costa, J.P., and Pereira, M.V.F.: 'Power system expansion planning under uncertainty', IEEE Trans. Power Syst., 1993, 8, (1), pp. 129-136

5 David, A.K., and Wen, F.S.: 'Transmission planning and investment under competitive electricity market environment'. Proc. IEEE Power Engineering Society Summer Meeting, 15-19 July 2001, Vol. 3, pp. $1725-1730$

6 Wong, W., Chao, H., Julian, D., Lindberg, P., and Kolluri, S. 'Transmission planning in a deregulated environment'. Proc. IEEE Conf. on Transmission and Distribution 1999, 11-16 April 1999, Vol. 1, pp. $350-355$

7 Hashimoto, S.H., Romero, R., and Mantovan, J.R.S.: 'Efficient linear programming algorithm for the transmission network expansion planning problem', IEE Proc. Gener., Transm. Distrib., 2003, 150, (5), pp. $536-542$

8 EPRI: 'Transmission Planning in an Open Access Environment' (EPRI, Palo Alto, CA, 1997)

9 Stoll, H.G.: 'Least-cost electric utility planning' (John Wiley \& Sons, 1989)

10 The BPA Infrastructure Addition Summary available at: http://www transmission.bpa.gov/tbllib/Publications/Infrastructure/defaultfiles/ slide0001.htm 
11 R. Orans, S. Price, D. Lloyd, T. Foley and E. Hirst, 'Expansion of BPA Transmission Planning Capabilities', November 2001, available for download at http://www.ehirst.com/projects.html

12 'Moving toward probabilistic reliability assessment methods - a framework for addressing uncertainty in power system planning and operation' (EPRI, Plao Alto, CA, 2003)

13 Coxe, R and Ilic, M. 'System planning under competition' in Ilic, M., Galiana, F. and Fink, L. (Eds.) 'Power Systems Restructuring: Engineering and Economics' (Kluwer Academic Publishers, 1998), pp. 283-334

14 National Electricity Market Management Company Ltd (NEMMCO) website: www.nemmco.com.au

15 Bhattacharya, K., Bollen, M.H.J., and Daalder, J.E.: 'Operation of reconstructed power systems' (Kluwer Academic Publishers, 2001)

16 Shirmohammadi, D., Rajagopalan, C., Alward, E.R., and Thomas, C.L.: 'Cost of transmission transactions: an introduction', IEEE Trans Power Syst, 1991, 6, (4), pp. 1546-1560

17 Shirmohammadi, D., Filho, X.V., Gorenstin, B., and Pereira, M.V.P.: 'Some fundamental technical concepts about cost-based transmission pricing', IEEE Trans. Power Syst., 1996, 11, (2), pp. 1002-1008

18 Stoft, S.: 'Power system economics' (IEEE Press, Ascataway, NJ, 2002)

19 Holland, J.: 'Adaptation in natural and artificial systems' (University of Michigan Press, Ann Arbor, ,MI, 1975)
20 Momoh, J.A.: 'Electrical power system applications of optimization' (Marcel Dekker Inc, 2001)

21 Dong, Z.Y., Makarov, Y.V., and Hill, D.J.: 'Power system small signal stability analysis using genetic optimization', Electr. Power Syst. Res., 1998, 46, pp. 195-204

22 Wong, K.P., and Wong, Y.W.: 'Genetic and genetic/simulatedannealing approaches to economic dispatch', IEE Proc., Gener. Transm. Distrib., 1994, 141, pp. 685-692

23 Mahfoud, S.W.: 'Population size and genetic drift in fitness sharing' in Whitile, L.D. and Vose, M.D. (Eds.) 'Foundations of Genetic Algorithms 3' (Morgan Kaufmann Publishing, Inc, 1995), pp. $185-223$

24 Deb, K.: 'Multi-objective optimization using evolutionary algorithms' (John Wiley \& Sons, Ltd, 2001)

25 National Electricity Market Management Company Limited (NEMMCO), Statement of opportunities (SOO), 2002, 2003 \& 2004, available from the NEMMCO website at: http://www.nemmco. com.au/nemgeneral/SOO_2004.htm

26 NEMMCO, Interconnector Development in the NEM: A Report by the Interconnector Process Working Group, June 2001, available from http:/ www.nemmco.com.au/transmission distribution/173-0104.htm

27 NEMMCO, Interconnector Limits for $M \overline{T P} A S A$, Feb, 2004, available for download from the NEMMCO website at: http://www.nemmco. com.au/dispatchandpricing/173-0183.htm 